\title{
A comparative study of misoprostol versus surgical management of incomplete and missed miscarriage
}

\author{
Monica Verma, Vibhuti Thakur*, Pratibha Awasiya
}

Department of Obstetrics and Gynecology, M. G. M. Medical College and M. Y. Hospital, Indore, Madhya Pradesh, India

Received: 23 September 2016

Accepted: 28 September 2016

*Correspondence:

Dr. Vibhuti Thakur,

E-mail: drvibhuti01@gmail.com

Copyright: (c) the author(s), publisher and licensee Medip Academy. This is an open-access article distributed under the terms of the Creative Commons Attribution Non-Commercial License, which permits unrestricted non-commercial use, distribution, and reproduction in any medium, provided the original work is properly cited.

\section{ABSTRACT}

Background: The aim of this study is to assess the effectiveness and acceptability of using vaginal Misoprostol for management of spontaneous incomplete and missed miscarriage as an alternative to direct vaginal surgical evacuation in our setting and also to compare the efficacy and patient satisfaction of the medical method with surgical method in same.

Methods: this is a prospective comparative study performed on randomly divided 200 patients in two groups. Each group of patients are case of missed or incomplete abortion in first trimester.(5-12 weeks). Group one received Misoprostol tablet $600 \mathrm{mcg}$ single dose per vaginally, and second group underwent surgical vaginal evacuation directly under local anesthesia (para-cervical block . both groups were compared in terms of success, complications, pain and patient satisfaction.

Results: $97 \%$ success rates were obtained in the medical treatment group. Surgical group had 95\% success rates. 3 patients underwent repeat surgical evacuation in the medical group. Bleeding was more and prolonged in the patients managed by Misoprostol, 27\% patients had moderate bleeding. Though bleeding was less in the surgical group but there was excruciating pain and weakness as the procedure being done under local anesthesia, 98\% patients experienced pain in surgical group. Satisfaction rates in the misoprostol group were $100 \%$.

Conclusions: Misoprostol is effective in complete evacuation of uterus in incomplete and missed miscarriage. Patients are highly satisfied with the misoprostol treatment as they didn't have to get hospitalized. The bleeding was more or less like menstrual bleeding which did not affect the daily chores of the women. It is as effective as surgical evacuation and patient satisfaction is much more than the surgical evacuation.

Keywords: Incomplete abortion, Missed abortion, Misoprostol, Vaginal evacuation

\section{INTRODUCTION}

Approximately $11-15 \%$ of pregnancies end in spontaneous first trimester miscarriage. ${ }^{1}$ Around 56 million abortions occur each year in the world with a little under half done unsafely. ${ }^{2,3}$ Unsafe abortions are defined by WHO (World Health Organization) as abortions performed by people lacking the necessary skills or in an environment that does not fulfil minimal medical standards, or both. ${ }^{4,5}$
When performed legally and safely, induced abortions do not increase the risk of long term mental or physical problems. ${ }^{6}$ In contrast, unsafe abortions causes 47,000 deaths and 5 million hospital admissions each year. ${ }^{6,7}$

Safe and effective treatment for incomplete abortion is an important way to reduce abortion related morbidity and mortality. Medical methods for treatment of incomplete abortion require few resources and can be administered by low and midlevel providers. Surgical methods are highly effective for treatment of incomplete abortion. 
However, these treatments require trained providers, special equipment, sterile conditions and often aneasthesia. All of which are limited in many settings.

Aims and objectives of the study were;

1. To study the role of Misoprostol in 1st trimester incomplete and missed abortions.

2. The aim of this study is to assess the effectiveness and acceptability of using vaginal Misoprostol for management of spontaneous incomplete and missed miscarriage as an alternative to direct vaginal surgical evacuation in our setting.

3. To compare the efficacy and patient satisfaction of the medical method with surgical method in treating patients with a miscarriage in a randomized setting.

4. To study the incidence and risk factors of immediate complications of medical and surgical induced miscarriage.

\section{METHODS}

The present study was conducted in the Department of Obstetrics and Gynecology, M.G.M. Medical College and M.Y. Hospital, Indore (M.P.) during the period of September 2014 to September 2015.This is a prospective comparative study performed on 200 patients with first trimester incomplete and missed miscarriage between 5 and 12 weeks. They were divided into two groups randomly.

1. Received Misoprostol tablet $600 \mathrm{mcg}$ single dose per vaginally.

2. Underwent surgical vaginal evacuation directly under local anesthesia (para-cervical block).

\section{Inclusion criteria}

1. Patient diagnosed incomplete or missed abortion clinically and by ultrasonography

2. General condition fair

3. Blood pressure $120 / 80$

4. Pulse $80 / \mathrm{min}$

5. No h/o of diabetes, asthma, epilepsy, cardiac disease, hypersensitivity to misoprostol

6. Clinical hemoglobin $>10$ gram.

7. No signs of sepsis

8. Willing for follow up after 15 days

9. Gestational age $<12$ weeks

10. Clinically not diagnosed ectopic pregnancy.

\section{Exclusion criteria}

1. Patient diagnosed threatened abortion clinically and by ultrasonography

2. General condition poor

3. Blood pressure $140 / 100$

4. Pulse $120 / \mathrm{min}$

5. H/o of diabetes, epilepsy, asthma, cardiac disease, hypersensitivity to misoprostol
6. Clinical hemoglobin $<10$ gram

7. Sign of sepsis

8. Cannot come for follow up

9. Gestational age $>12$ weeks

10. Hypersensitivity to misoprostol

11. Suspected ectopic pregnancy.

\section{Methdology}

Patient's admitted with complaints of amenorrhea followed by bleeding

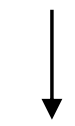

Diagnosis of incomplete or missed abortion confirmed by clinical and USG findings. Routine investigations done.

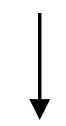

After applying for exclusion criteria patient divided into 2 groups (randomly)

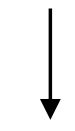

Group A - 600 mcg Misoprostol orally

Group B - evacuation under local anesthesia (paracervical block)

Follow up after 15 days.

In follow up USG done to confirm complete evacuation of the retained products. Also amount of bleeding, sepsis, pain, requirement for re evacuation and patient satisfaction was assessed by a detailed history pro-forma.

\section{RESULTS}

Table 1: Distribution of cases.

\begin{tabular}{|lllll|}
\hline Cases & $\begin{array}{c}\text { Medical } \\
(\mathbf{n}-100)\end{array}$ & \multicolumn{3}{c|}{$\begin{array}{l}\text { Surgical } \\
(\text { n-100) }\end{array}$} \\
\cline { 2 - 5 } & NO. & $\%$ & No. & \% \\
\hline Incomplete & 42 & $42 \%$ & 53 & $53 \%$ \\
\hline Missed & 58 & $58 \%$ & 47 & $47 \%$ \\
\hline Total & 100 & $100 \%$ & 100 & $100 \%$ \\
\hline
\end{tabular}

Table 2: Parity wise distribution of cases.

\begin{tabular}{|c|c|c|c|c|}
\hline \multirow[t]{2}{*}{ Parity } & \multicolumn{2}{|c|}{$\begin{array}{l}\text { Medical } \\
(\mathrm{n}=100)\end{array}$} & \multicolumn{2}{|c|}{$\begin{array}{l}\text { Surgical } \\
(\mathrm{n}=100)\end{array}$} \\
\hline & No. & $\%$ & No. & $\%$ \\
\hline PRIMI G1 & 37 & $37 \%$ & 40 & $40 \%$ \\
\hline G2 & 28 & $28 \%$ & 30 & $30 \%$ \\
\hline G3 & 23 & $23 \%$ & 19 & $19 \%$ \\
\hline G4 & 10 & $10 \%$ & 8 & $8 \%$ \\
\hline$>/=$ G5 & 2 & $2 \%$ & 3 & $3 \%$ \\
\hline Total & 100 & 100 & 100 & 100 \\
\hline
\end{tabular}


In the present study $42 \%$ patients in medical group and $53 \%$ patients in surgical group were incomplete cases.

In both groups, majority of patients were primigravida.

Table 3: Age wise distribution of cases.

\begin{tabular}{|lllll|}
\hline $\begin{array}{l}\text { Age } \\
\text { (Years })\end{array}$ & Nedical $(n=100)$ & \multicolumn{2}{l|}{ Surgical $(n=100)$} \\
\hline$<19$ & 4 & $\%$ & No. & $\%$ \\
\hline $20-25$ & 70 & $7 \%$ & 3 & $3 \%$ \\
\hline $26-30$ & 18 & $18 \%$ & 77 & $77 \%$ \\
\hline $31-35$ & 14 & $14 \%$ & 4 & $16 \%$ \\
\hline Total & 100 & $100 \%$ & 100 & $100 \%$ \\
\hline
\end{tabular}

Table 4: Education wise distribution of cases.

\begin{tabular}{|lllll|}
\hline \multirow{2}{*}{ Education } & \multicolumn{2}{l}{$\begin{array}{l}\text { Medical } \\
(\mathbf{n = 1 0 0 )}\end{array}$} & \multicolumn{2}{l|}{$\begin{array}{c}\text { Surgical } \\
(\mathbf{n}=100)\end{array}$} \\
\cline { 2 - 5 } & No. & $\mathbf{\%}$ & No. & $\%$ \\
\hline Illiterate & 62 & $62 \%$ & 51 & $51 \%$ \\
\hline Primary Education & 12 & $12 \%$ & 15 & $15 \%$ \\
\hline Middle School & 18 & $18 \%$ & 22 & $22 \%$ \\
\hline High School & 8 & $8 \%$ & 12 & $12 \%$ \\
\hline Total & 100 & $100 \%$ & 100 & $100 \%$ \\
\hline
\end{tabular}

Table 5: Clinical outcome of the study group.

\begin{tabular}{|lllll|}
\hline & \multicolumn{2}{c}{ Medical } & \multicolumn{2}{c|}{ Surgical } \\
\hline No. & \% & No. & $\%$ \\
\hline $\begin{array}{l}\text { 1. Success of treatment } \\
\text { method }\end{array}$ & 97 & $97 \%$ & 95 & $95 \%$ \\
\hline $\begin{array}{l}\text { 2. Incidence of side } \\
\text { effects }\end{array}$ & 31 & $31 \%$ & 98 & $98 \%$ \\
\hline $\begin{array}{l}\text { 3. Tolerability of the } \\
\text { method of treatment }\end{array}$ & 97 & $92 \%$ & 42 & $42 \%$ \\
\hline $\begin{array}{l}\text { 4. Incidence of } \\
\text { excessive post abortive } \\
\text { bleeding }\end{array}$ & 27 & $27 \%$ & 8 & $8 \%$ \\
\hline
\end{tabular}

Table 6: Complication.

\begin{tabular}{|c|c|c|c|c|}
\hline \multirow[t]{2}{*}{ Complication } & \multicolumn{2}{|c|}{$\begin{array}{l}\text { Medical } \\
(\mathrm{n}=100)\end{array}$} & \multicolumn{2}{|c|}{$\begin{array}{l}\text { Surgical } \\
(\mathrm{n}=100)\end{array}$} \\
\hline & No. & $\%$ & No. & $\%$ \\
\hline \multicolumn{5}{|l|}{ Bleeding } \\
\hline 1. Mild & 73 & $73 \%$ & 92 & $92 \%$ \\
\hline 2. Moderate & 27 & $27 \%$ & 8 & $8 \%$ \\
\hline 3. Severe & - & - & - & - \\
\hline Pain & & & & \\
\hline 1. No Pain & 76 & $76 \%$ & - & - \\
\hline 2. Mild & 24 & $24 \%$ & 69 & $69 \%$ \\
\hline 3. Moderate & - & - & 31 & $31 \%$ \\
\hline $\begin{array}{l}\text { Foul smelling vaginal } \\
\text { discharge }\end{array}$ & - & - & - & - \\
\hline H/O Re-evacuation & 3 & $3 \%$ & 5 & $5 \%$ \\
\hline $\begin{array}{l}\text { Complication } \\
\text { (perforation) }\end{array}$ & - & - & 1 & $1 \%$ \\
\hline
\end{tabular}

Most of the patients in both groups are illiterate (Table 4).

Side effects are more in surgical group while post abortive bleeding is noticed more in medical group. Also medical treatment is tolerated well $(92 \%$ Vs $42 \%)$.

There was more bleeding, during surgical procedure with higher incidence of pain.

Table 7: Patient's satisfaction.

\begin{tabular}{|lllll|}
\hline \multirow{2}{*}{ Satisfaction } & \multicolumn{2}{c|}{$\begin{array}{l}\text { Medical } \\
\text { (n= 100) }\end{array}$} & \multicolumn{2}{l|}{$\begin{array}{l}\text { Surgical } \\
(\mathbf{n}=100)\end{array}$} \\
\cline { 2 - 6 } & No. & \% & No. & $\%$ \\
\hline Completely & 95 & $95 \%$ & 0 & $\%$ \\
\hline Partially & 5 & $5 \%$ & 76 & $76 \%$ \\
\hline Not Satisfied & 0 & 0 & 24 & $24 \%$ \\
\hline $\begin{array}{l}\text { Shall undergo same } \\
\text { treatment if required next } \\
\text { time }\end{array}$ & 97 & $97 \%$ & 42 & $42 \%$ \\
\hline $\begin{array}{l}\text { Shall recommend to a } \\
\text { friend }\end{array}$ & 97 & $97 \%$ & 26 & $26 \%$ \\
\hline
\end{tabular}

Medical group patients are highly satisfied as compared to surgical group.

Table 8: Statistical correlation of symptoms and outcome.

\begin{tabular}{|c|c|c|c|c|c|}
\hline \multirow[t]{2}{*}{ Complication } & \multicolumn{2}{|c|}{$\begin{array}{l}\text { Medical } \\
(\mathrm{n}=100)\end{array}$} & \multicolumn{2}{|c|}{$\begin{array}{l}\text { Surgical } \\
(\mathrm{n}=100)\end{array}$} & \multirow[t]{2}{*}{$\begin{array}{l}\mathbf{P} \\
\text { value }\end{array}$} \\
\hline & No. & $\%$ & No. & $\%$ & \\
\hline Bleeding & 27 & 27 & 8 & 8 & 0.026 \\
\hline Pain & 24 & 24 & 98 & 98 & 0.000 \\
\hline $\begin{array}{l}\text { Satisfaction } \\
\text { (complete plus } \\
\text { partial) }\end{array}$ & 100 & 100 & 76 & 76 & 0.043 \\
\hline No satisfied & 0 & $0 \%$ & 24 & $24 \%$ & 0.039 \\
\hline $\begin{array}{l}\text { Shall undergo } \\
\text { same treatment }\end{array}$ & 97 & 97 & 42 & 42 & 0.047 \\
\hline $\begin{array}{l}\text { Recommend to } \\
\text { other friend }\end{array}$ & 97 & 97 & 26 & 26 & 0.002 \\
\hline
\end{tabular}

In the present study, there were $27 \%$ patients in the medical group and $8 \%$ patients in the surgical group were bleeding. Majority of patient i.e. $100 \%$ of medical group and $76 \%$ patients in the surgical group were of complete plus partial satisfaction.

In the present study, young women having incomplete and missed abortion with lesser (more common) parity were studied. $97 \%$ success rates were obtained in the medical treatment group. Surgical group had $95 \%$ success rates. 3 patients underwent repeat surgical evacuation in the medical group.

Bleeding was more and prolonged in the patients managed by Misoprostol $27 \%$ patients had moderate 
bleeding. Though bleeding was less in the surgical group but there was excruciating pain and weakness the procedure being done under local anesthesia. 98\% patients experienced pain in surgical group.

Surprisingly 5 patients required a Re-evacuation in the surgical group and only three in the medical group. The reason most probably was the procedure being blind and affected by the pain experienced by the patients in the surgical group. The three patients of the medical group were labeled being failure of method and were offered surgical evacuation for the same. There was one perforation in the surgical group which was conservatively managed as the patient was stable hemodynamically.

Satisfaction rates in the misoprostol group were $100 \%$.

\section{DISCUSSION}

Success of any method was defined as complete evacuation of products of conception by an ultrasound and absence of any clinical symptoms. 97\% success rates were obtained in the medical group. High success rates have been found in many studies. $94.5 \%$ success was found in study at Madagascar and Maldova. ${ }^{8}$ SHOKY also reported $79.6 \%$ success with misoprostol and $100 \%$ in surgical evacuation. ${ }^{9} \quad(\mathrm{p}$ value $=0.0006)$ study conducted in Indian scenario by Beenuet et al, found medical method to be effective in $92 \%$ patients. ${ }^{10}$ Adisso et al recorded $99 \%$ success in medical management. ${ }^{11}$ Chung et al did not find very good successful outcomes in his study wherein the success rates were low being at only $50 \% .^{12}$ But all sort of complications serious and mild were less in the medical group in their study. On the contrary Adissoetal found $99 \%$ success rates in their study. ${ }^{11}$

The numbers of patients with post abortal bleeding were more in the medical group. It was statistically correlated and found to be significant ( $p$ value $=0.026$ ). Many studies conducted indicate similar results. Study by Md. Shokey et al found that bleeding was more with misoprostol treatment being of statistical significance ( $p$ value 0.0336$).{ }^{9}$ In study by Adisso et al, $5 \%$ patients in the medical group experienced heavy bleeding. ${ }^{11}$ All patients but 2 (grand multigravidas) complained of excruciating pain during and after the procedure. Though the grand multigravidas did complained of pain which subsided with oral pain killers. Only 24 patients in the medical group complained of having moderate amount of lower abdominal cramping pain.

$100 \%$ patients were satisfied with the medical management. The three patients that underwent evacuation later also said that they were happy at-least they tried to make things easy for their family. While only $76 \%$ patients were satisfied with the surgical evacuation. These patients showed despair of not being given the medical management. These results showed significant statistical correlation ( $\mathrm{p}$ value $=0.043$ ). Similar results were found in other studies whilst Madagascar 7 maldova conclude that the best features of medical treatment were it being quick, easy convenient, and also avoided surgical intervention and the related complications. ${ }^{8}$ The satisfaction level was as high as $97 \%$ in their study.

$97 \%$ patients said that they were willing to undergo same treatment in the next time if required. In the medical group, only $42 \%$ women said they would undergo same surgical evacuation. The statistics in this respect also showed correlation ( $\mathrm{p}$ value $=0.047$ ) the results suggest high tolerability of the method. Mdshoky et al also found similar tolerability in the two groups. ${ }^{9}$ Tolerability was also high in the study at Madagascar and Maldova which was conducted on 300 women. ${ }^{8}$ They found it to highly tolerable method rates being $75 \%$.

$97 \%$ women in the medical group said they would recommend the method to her friends. While only $26 \%$ women in the surgical group said so.

\section{CONCLUSION}

The estimated abortion percentage of known pregnancies was at $21 \%$ worldwide with $26 \%$ in developed countries and $20 \%$ in developing countries. ${ }^{3}$ Given its safety, efficacy, and ease of use, misoprostol is an important option for the treatment of women with incomplete abortion. This research study done by us shows how misoprostol can be provided in low-resource settings where demand for services may be high and availability of skilled providers and equipment are often scarce. Professional associations such as the American College of Obstetricians and Gynecologists recommend misoprostol for postabortion care and the World Health Organization has added misoprostol for the management of incomplete abortion and miscarriage to its Model List of Essential Medicines. ${ }^{13}$

The available Cochrane systematic review evidence suggest that expectant care as well as medical treatment with misoprostol are acceptable alternatives to routine vaginal surgical evacuation. $^{14}$

Funding: No funding sources Conflict of interest: None declared

Ethical approval: The study was approved by the Institutional Ethics Committee

\section{REFERENCES}

1. Steer C, Campbell S, Davies M, Mason B, Collins WP. Spontaneous abortion rates after natural and assisted conception. BMJ. 1989;299:1317-8.

2. Gilda S, Jonathan B, Susheela S, Akinrinola B, Popinchalk A, Ganatra B, et al. Abortion incidence between 1990 and 2014: global, regional, and subregional levels and trends. The Lancet. 2016. 
3. Sedgh G, Singh S, Shah IH, Ahman E, Henshaw K, Bankole A. Induced abortion: Incidence and trends worldwide from 1995 to 2008 (PDF). The Lancet. 2012;379(9816):625-32.

4. Grimes DA, Benson J, Singh S, Romero M, Ganatra B, Okonofua FE. Unsafe abortion: the preventable pandemic. Lancet. 2006;368:1908-19.

5. Singh S. Hospital admissions resulting from unsafe abortion: Estimates from 13 developing countries. Lancet. 2006;368:1887-92.

6. Lohr PA, Fjerstad M, Desilva U, Lyus R. Abortion. BMJ. 2014;348:f7553.

7. Shah I, Ahman E. Unsafe abortion: global and regional incidence, trends, consequences, and challenges (PDF). J Obstet Gynaecol Can. 2009;31(12):1149-58.

8. Madagascar: Adapting the $400 \mathrm{mcg}$ sublingual misoprostol regimen for PAC into national reproductive health norms. A large maternity hospital in Madagascar recently completed a study comparing a $400 \mathrm{mcg}$ sublingual dose to a $600 \mathrm{mcg}$ oral dose of misoprostol for treatment of incomplete abortion.

9. Shokry M, Fathalla M, Hussien M, Ashraf A. Eissa Vaginal misoprostol versus vaginal surgical evacuation of first trimester incomplete abortion: Comparative study. Middle East Fertility Society Journal. 2013.

10. Teixeira-da-Silva BJ, Campos I. Vaginal misoprostol in the management of first-trimester missed abortions. International Journal of Gynecology and Obstetrics. 2000;71:53-7.

11. Addisso A, Jacobsen G, Sandhu R. Medical management of non-viable early first trimester pregnancy. Int J Gynaecol Obstet. 1999;67:9-13.

12. Chung TK, Lee DT, Cheung LP. Spontaneous abortion: a randomized, controlled trial comparing surgical evacuation with conservative management using misoprostol. Fertil Steril. 1999;71(6):1054-9.

13. Unedited Draft Report of the $17^{\text {th }}$ Expert Committee on the Selection and Use of Essential Medicines. Geneva, Switzerland: World Health Organization. 2009.

14. Neilson JP, Gyte GM, Hickey M, Vazquez JC, Dou L. Medical 226 treatments for incomplete miscarriage (less than 24 weeks). 227 Cochrane Database Syst rev. 2010(1):CD007223. http://dx.doi.org/10.1002/14651858.

CD007223.pub2. Review. Update in: http://www.ncbi.nlm.nih.gov/pubmed/23543549 Cochrane Database Syst Rev. 2013(3):CD007223.

Cite this article as: Verma M, Thakur V, Awasiya P. A comparative study of misoprostol versus surgical management of incomplete and missed miscarriage. Int J Reprod Contracept Obstet Gynecol 2016;5:3654-8. 